\title{
ИСПОЛЬЗОВАНИЕ ЭЛЕКТРОННЫХ ПЛАТЕЖЕЙ В БАНКОВСКОЙ ПРАКТИКЕ
}

\section{USE OF ELECTRONIC PAYMENTS IN BANK PRACTICE}

G. Murtazoeva

Summary. The article is devoted to the study of the features of the use of electronic payments in banking practice. Special attention is paid to the importance and role of electronic payment banking system for the stability of the national economy and public finance. In addition, the tasks of using electronic payments by banks have been highlighted. Particular emphasis is placed on the use of electronic payment services by banks in the process of servicing individuals.

Keywords: bank, electronic payments, Internet banking, finance, stability, system.

\author{
Муртазоева Гулноз Икромовна \\ Российско-Таджикский (славянский) Университет, \\ Душанбе, Таджикистан \\ Ikrom.fu@gmail.com
}

Аннотация. Статья посвящена исследованию особенностей использования электронных платежей в банковской практике. Отдельное внимание уделено значению и роли электронной платежной банковской системы для стабильности национальной экономики и государственных финансов. Кроме того, выделены задачи использования электронных платежей банками. Особый акцент сделан на применении банками электронных платежных сервисов в процессе обслуживания частных лиц.

Ключевые слова: банк, электронные платежи, Интернет-банкинг, финансы, стабильность, система.

Однако, несмотря на успешность использования банками электронных платежных систем как на международном, так и на национальном уровнях, не теряет своей актуальности задача их улучшения и постоянной модификации.

Таким образом, обозначенные обстоятельства объясняют постоянный рост интереса к проблеме развития банковских электронных платежных систем, что и предопределило выбор темы данной статьи.

Исследованиями в направлении развития платежных систем занимаются такие зарубежные ученые, как G. Reynolds, F. Stefan, M. Woodford, K. Fullencamp, Saleh M. Nsouli, S. Turnbull.

Более подробно на различных аспектах развития электронных платежных систем и денег сосредоточили свое внимание М.С. Деменков, Х.А. Засадная, Я.М. Кривич, Т. А. Медведь, Т. В. Шевчук и др.

Более предметно влияние электронных платежных систем на финансовую систему страны и на ее составляющие исследуется в работах отечественных авторов, к числу которых можно отнести Д.Е. Евсюкова, Д.А. Кочергина, Н. А. Тлишеву, А. В. Колесника.

Высоко оценивая проведенные исследования, следует отметить, что целый ряд вопросов развития механизмов электронных платежей в банковской системе, 
Таблица 1. Наиболее развитые электронные платежные системы банков РФ

\begin{tabular}{|l|l|}
\hline Банк & Технологии электронных платежных систем \\
\hline Сбербанк России & Сбербанк Интернет-банкинг; мобильный банкинг; терминалы для осуществления платежей \\
\hline ВТБ & VTB Банк Клиент-банк, GSM-банкинг, интернет-банкинг VTBOnline \\
\hline Альфабанк, & Альфа-Банк «Интернет-банкинг + SMS-банкинг + e-mail-банкинг», пакет услуг «Альфа-Престиж» \\
\hline Газпромбанк & «Клиент-банк»; Интернет-Клиент-банк; мобильный банкинг \\
\hline Банк ФК Открытие & Открытие Интернет банкинг + мобильный банкинг + Открытие-телевойс \\
\hline $\begin{array}{l}\text { Московский кредитный } \\
\text { банк }\end{array}$ & МКБ банкоматы, терминалы для осуществления платежей, GSM-банкинг, интернет-банкинг МкБ Online \\
\hline Райффайзен & Райффайзен Банк Аваль Интернет банкинг + мобильный банкинг + Аваль-телевойс \\
\hline Ситибанк & $\begin{array}{l}\text { Сити Интернет-банкинг Citi-Online, Мобильный банкинг, SMS-банкинг, Контакт-центр, система } \\
\text { моментальных платежей Portmone }\end{array}$ \\
\hline
\end{tabular}

в контексте стремительного развития финансовых инноваций, а также распространения связанных с такими инновациями рисков, еще остаются нерешенными. Это касается, в частности, формирования национального платежного пространства, усовершенствования платежной инфраструктуры, развития механизмов взаимодействия всех участников платежных систем и урегулирования взаимоотношений между ними в соответствии с лучшей мировой практикой.

Таким образом, цель статьи заключается в исследовании особенностей использования электронных платежей в банковской практике.

Электронные платежи банковскими учреждениями осуществляются в рамках национальной системы массовых электронных платежей, которая представляет собой внутригосударственную банковскою платежную систему, в которой расчеты за товары и услуги, получение наличных и другие операции осуществляются с помощью платежных смарт-карт по технологии, разработанной центральным банком страны [3]. Банки не только участвуют в этой системе как обычные плательщики и получатели средств, но и выполняют роль посредников в платежах, благодаря чему в режиме реального времени доставляются денежные средства от плательщика к получателю.

С учетом вышеизложенного, можно отметить, что в современных условиях основными задачами использования электронных платежей банками являются:

- поддержание устойчивости денежного обращения и стабильности национальной денежной единицы на основе реализации функции денег, являющихся средством платежа;

- предоставление субъектам рынка платежных средств и инструментов в необходимом объеме и с учетом требуемой функциональности;

- обеспечение своевременности и точности исполнения всех расчетов и платежей;
- повышение надежности функционирования платежных и расчетных механизмов;

- содействие динамичному развитию национальной экономики.

Помимо общегосударственного значения электронных платежей, реализуемых банковскими учреждениями, отдельный акцент также следует сделать на том, что они играют очень важную роль в развитии и усовершенствованию услуг, которые предоставляются частному сектору.

Благодаря возможностям современных электронных платежных систем сегодня стали привычными понятия: telebanking - дистанционные операции по телефону; PC-banking - операции через персональный компьютер, handyipocketbanking - операции с помощью мобильного телефона; direct banking - прямые банковские операции; phonebanking, faxbanking - операции по факсу;

Популярность электронных платежей, которые предлагают банки, во многих странах мира ежегодно растет. Согласно данным консалтинговой компании McKinsey\&Company, в настоящее время с помощью компьютеров и мобильных устройств жители России осуществляют около 47\% расчетов. К примеру, в Польше с использованием электронных платежных средств проходит более 95\% розничных операций [4].

Сегодня электронные платежи в России используют многие банковские учреждения. Наиболее успешными и технологичными участниками рынка являются Сбербанк России, ВТБ, Альфабанк, Газпромбанк, Банк ФК Открытие, Московский кредитный банк, Райффайзен, Ситибанк (см. табл. 1).

По словам банкиров, ключевым аргументом продвижения электронных платежей является то, что себестоимость операций, осуществляемая с их использованием, гораздо ниже, чем операций, выполняемых в отделени- 
ях [5]. Однако такая удобная для потребителей ситуация может длиться недолго - можно прогнозировать введение банками платы за обслуживание электронных платежей или повышение действующих расценок.

Таким образом, подводя итоги, отметим, что особенности использования банками электронных платежей на современном этапе связаны с действием таких факторов как глобализация, усложнение организационно-тех- нических и технологических информационных систем, а также взаимосвязей между отдельными элементами платежных систем в международном измерении, увеличение объемов платежей, количества участников и скорости расчетов. Поэтому электронные платежи, проводимые банками, имеют большое значение как для обеспечения устойчивости национальной финансовой системы, так и для развития и улучшения обслуживания частных клиентов.

\section{ЛИТЕРАТУРА}

1. Impact of digital innovation on the processing of electronic payments and contracting: an overview of legal risks. Frankfurt am Main: European Central Bank, 2017. $145 \mathrm{p}$.

2. Hampshire, Chris A mixed methods empirical exploration of UK consumer perceptions of trust, risk and usefulness of mobile payments // International journal of bank marketing. 2017. Volume 35; Issue 35; pp 354-369.

3. Semerikova, Ekaterina Payment instruments choice of Russian consumers: reasons and pain points // Journal of enterprising communities: people and places in the global economy. 2019. Volume 14: Number 1; pp 22-41.

4. Аббасов А.М., Мамедов 3. Ф., Алиев С. А. Цифровизация банковского сектора: новые вызовы и перспективы // Экономика и управление. 2019. № 6(164). C. 81-89.

5. Никонов А.А., Стельмашонок Е. В. Анализ внедрения современных цифровых технологий в финансовой сфере // Научно-технические ведомости Санкт-Петербургского государственного политехнического университета. Экономические науки. 2018. Т. 11. № 4. С. 111-119.

(c) Муртазоева Гулноз Икромовна ( Ikrom.fu@gmail.com ).

Журнал «Современная наука: актуальные проблемы теории и практики»

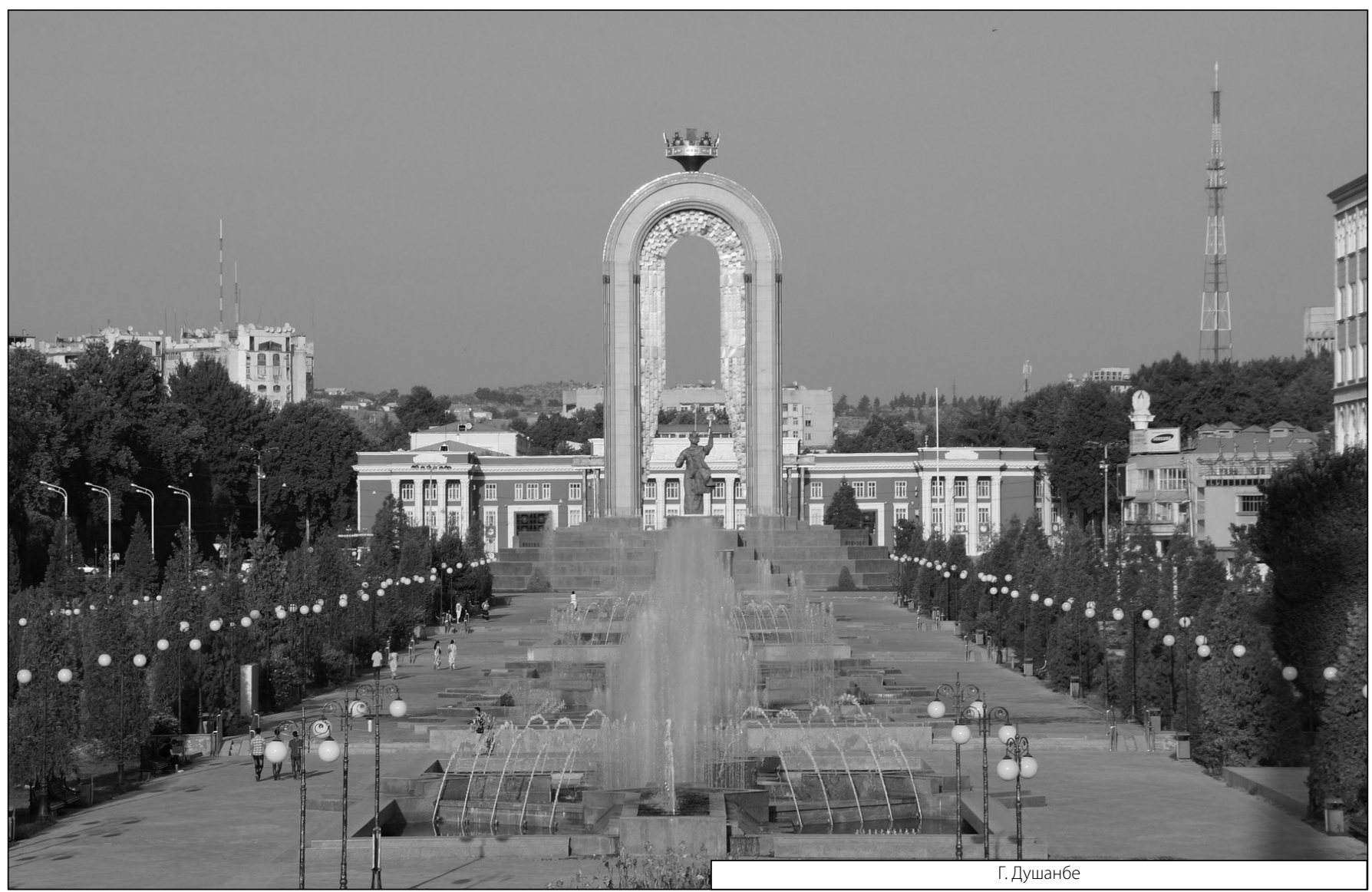

